\title{
Testing Attitudes, Social Desirability and Behavioral Regulations as Moderators of Implicit-Explicit Exercise Cognition Discrepancies in Iranian Students
}

\author{
Tanya Berry \\ University of Alberta Faculty of Physical Education and Recreation \\ Parvaneh Taymoori ( $\nabla$ parvaneh.tay@gmail.com ) \\ social determinants of health research center \\ Kohestan Shirzadi \\ Universidad de Puerto Rico Recinto de Ciencias Medicas \\ Tahereh Pashaei \\ Kurdistan University of Medical Sciences \\ Afshin Bahamani \\ Kurdistan University of Medical Sciences
}

\section{Research}

Keywords: implicit associations, explicit cognition, social desirability, behavioral regulations implicit-explicit discrepancy, Iranian

Posted Date: August 10th, 2020

DOl: https://doi.org/10.21203/rs.3.rs-54029/v1

License: (우 (1) This work is licensed under a Creative Commons Attribution 4.0 International License. Read Full License 


\section{Abstract}

Background: Although there is interest among regarding implicit-explicit exercise cognition discrepancies, there is mixed evidence regarding what moderates the relationship between implicitly and explicitly measured constructs. This study examined this issue with evaluations of exercise relative to health or appearance in a sample of Iranian adolescents.

Methods: Participants were 471 students enrolled in grades 9 to 12 from Kurdistan, Iran, of whom 269 (54.9\%) were female. The possible moderators included behavioral regulations, explicit attitudes, and social desirability. All students completed questionnaire measures of physical activity behavior, attitudes, social desieality and behavioral regulation. They also completed two Go/No Go Association tasks to measure implicit evaluations of exercise relative to health and apperarance.

Results. Attitude was a significant moderator of discrepancies between implicit evaluations of exercise with health and health motives. Interjected regulation moderated implicit-explicit appearance discrepancies in the health models. Participants with low social desirability and negative implicit appearance scores had the highest appearance motivation.

Conclusions: Investigating implicit-explicit discrepancies provides insight into the development of interventions targeting exercise behavior among Iranian adolescents.

\section{Background}

Many researchers have successfully applied two major motivation theories, social cognitive $(1,2)$ and the theory of planned behavior(3-5), to explain exercise behavior. However, these theories may neglect more automatically activated evaluations by focusing only on explicit evaluations. More recent research has focused on relationships between implicitly and explicitly measured motives $(6,7)$ and there is some indication that implicitly measured evaluations contribute to predicting exercise after controlling for related explicitly measured evaluations(6-8). Explicitly measured evaluations are thought to be consciously available, deliberately formed, and accessible to self-report. On the other hand, implicitly measured attitudes are likely more automatically activated and we may or may not be aware of them(9). There is some evidence that these more automatically-activated evaluations may be related to the regulation of exercise behavior(10). A systematic review and correlation meta-analysis reported a small, significant, and positive correlation between implicit evaluations and exercise. Howver, these relationships were not the result of moderating effects, such as study design or topic, participants' age, or other characteristics(11).

Relationships between implicitly and explicitly measured exercise evaluations have not been consistent. Hyde et al. argued if explicit and explicit systems are functionally separated from each other, they are expected to have little coordination(6). Others have argued against assuming that implicit and explicit exercise-related evaluations are independent of each other but may be moderated by some behavioral regulations and explicitly measured attitude(7). Others have also concluded that the independence of implicit and explicit evaluations depends on the context of attitude(12). Within the exercise domain, 
investigations into implicit and explicit discrepancies (IEDs) have been inconsistent with some studies showing moderately/weakly positive correlations $(8,13)$ while others have observed no relationship(14).

Researchers have also examined (IEDs) and their effect on exercise(15). For example, if one has somewhat undesirable automatic evaluations of Physical Activity (PA), but positive explicit evaluations, the evaluations might differentially influence decisions to approach or avoid that occasion to be physically active(10). In one example of bodybuilding workouts, the ideal frequency of training increased with less (IED) (16). However, Chevance and colleagues concluded there is little empirical evidence yet regarding a real discrepancy amongst the implicit processes that regulate exercise(11). Other studies have shown a negative effect of (IED) on exercise behavior(7, 10). In Berry and colleagues' study, greater (IED) was negatively related to the duration of exercise in one year(16).

Individual difference and situational moderators of the relationship between (IEDs) and exercise behavior need to be identified. For example, the value placed on the likelihood of exercise-related outcomes (e.g., health, appearance) and evaluation of these outcomes might be associated with (IEDs) such that this value is a likely moderator of(IEDs) as reported by Berry et al. (17). Specific to adolescents, positive outcome expectancies (health, fitness or appearance) appear to be more predictive of exercise $(7,17)$, especially among older adolescents(18). Explicitly measured appearance and health outcome expectancies of exercise showed positive and moderate relationships with adolescent exercise (19-21). One study found positive automatic evaluations between exercise and social/appearance outcomes in adolescents but no similar relationship between exercise and desirable or undesirable health outcomes(22). Social desirability is another possible moderator to consider within the exercise domain $(7,23)$. It is possible that explicit evaluations of exercise among youth are influenced by social desirability althoguh several reserachers have found that social desirability was not a significant moderator among adults(6, 7).

Self-Determination Theory (SDT) has been widely used to study motivation in exercise contexts(24). (SDT) bases personal behavior on intrinsic and extrinsic motivation. Extrinsically motivated behaviors are expressed in four regulations: the first two, external and introjected regulations are considered controlled regulatory forms, while the second two, identified and integrated regulation are more autonomous regulatory forms. External regulation is the least self-determined. These occur when an individual participates in (PA) not for interest or enjoyment in the activity itself, but to get rewards, avoid punishment, or satisfy external contingencies. Introjected regulation or performing to obtain social approval or avoiding internal pressure, is considered to be controlled because behavior is still enforced, only now by internal pressures. Identified regulation occurs when a participant values and judges the separable outcomes of exercise as being individually important. The integrated regulations involve accepting and integrating behavior in others aspects of the self. Integrated regulations together with intrinsic motivation, have been emphasized as vital factors in maintenance of (PA) and exercise(25).

Behavioral regulations have been investigated as possible moderators between (IEDs) and PA with mixed results. Hyde and colleagues found that introspective access moderated relationships between (IEDs) and (PA) (6) while Berry and colleagues showed a moderating role for identified regulations related to (IEDs) measuring associations with appearance(7). Eeffortful control (one aspect of self-regulation) was found to 
moderate associations between implicit evaluations and self-reported (PA) during leisure time among 150 highly active young adults(26).

Given the possible moderating role of behavioral regulations, explicit affective evaluations, and social desirability on (IEDs) in adults, the current study extended the question of whether similar modeation relationsips exist between (IEDs) and exercise in adolescents. Similarly, to Berry and colleagues(7) this study aimed to test (IEDs) relative to health or appearance and related evaluations. Additionally, this study is the first to examine these relationships in Iranian adolescents and might provide important implications for the development of interventions targeting exercise behavior in that population.

\section{Method}

\section{Participants}

Based on the results of a pilot study and using a .95 confidence level, it was concluded that a sample size of 534 would give adequate power. Adolescents were selected using a cluster random sampling method from three male high schools and three female high schools from nine schools located in Marivan, Iran. At each high school, three classes from each grade, 9 to 12, were selected for inclusion. The response rate was $96.2 \%$. $(n=514)$, after eliminating cases with missing data, data from 500 participants were included. The ethical committee of Kurdistan University of Medical Sciences approved the study by the Research Ethics Committee (ethics code: IR.MUK.REC.1398.202). The study investigator sent a written information sheet and consent form for the parents and participants to sign. The research purpose and instructions on how to complete the questionnaires were explained by a research assistant to the students. Data collection took place during physical education classes, and the questionnaires were administered to students in their classrooms.

\section{Measures}

All measures were presented in Farsi.

Physical activity behavior was measured using the Godin Leisure-Time Exercise Questionnaire (GLTEQ; Godin, Jobin, \& Bouillon, 1986; Godin \& Shephard, 1985). The GLTEQ is a self-report measure that asks participants to recall how many times during a 7-day period they participated in strenuous and moderate physical activity for more than 30 minutes. The measure was somewhat changed for this study to be consistent with the duration of the activity described in other instruments used in this study and health recommendations of Healthy People 2010 and the American Heart Association. An exercise index score was calculated by multiplying each reported exercise session of moderate activity by 5 , and strenuous activity by 9 , and summing the results. In the current study, when pilot tested with 45 Iranian male and female adolescents, two-week test-retest reliability was 0.81 .

Implicit evaluations. Two Go/No Go Association Tasks (GNATs) were used to measure evaluations of exercise relative to 1) health and 2) appearance. The target category (exercise) included words such as 
activity, exercise, running, football, volleyball, swim, walking and gym. The evaluation category included desirable/undesirable as exercise outcomes. The words used to represent health and appearance were selected after a pilot test with a random sample of 65 students ( 37 males and 32 female). Words were rated on 1 (not at all) - 5 (entirely) scale asking how much the word was related to health/ appearance. The words with the highest respective average were used in the (GNATs). For the health outcomes (GNAT), the words lincluded energetic/not energetic, strong/weak, relax/anxiety, healthy-sick, enjoyment/boredom depression/happiness, efficiency/inefficiency. For the appearance outcome (GNAT), words related to physical appearance Iranian cultural and social norms including beauty/ ugly, loose body/muscle body, short height/ long height, big belly/ flat belly, attractive / unattractive, lovely/ obnoxious, pale/pretty color. The distractor category included words of the same length as the target words that had nothing to do with exercise and were related to stationary (e.g., pens, notebooks). For example, the contrast word for the target exercise word 'Karate' was 'Klasor', which means notebook in Farsi.

At the start of each (GNAT), participants were told which words belonged within each category, (e.g., exercise/desirable, exercise/undesirable, stationary). They were instructed to press as quickly as possible the Go button if a word appeared within a block category, and to not press the Go button if the words do not belong to the specific block category. The response deadline for classifying targets considered 650 milliseconds (msec). Feedback was provided after each response: a red " $O$ " for an error and a blue " $\mathrm{X}$ " for the correct answer. Between each of the blocks of trials (48 trials in each block), there was a short break or the fixation cross of 500 milliseconds where participants are told what the next block pairings will be (e.g., exercise and good) and then they hit the spacebar to continue. Each of the four blocks ("go" categories of exercise/desirable, distractor/desirable, exercise/undesirable, distractor/undesirable) included 48 trials (192 total trials) and words were randomly selected for presentation. Block order was counter-balanced. The (GNAT) variant (health or appearance) order was also counterbalanced across participants.

Explicit Motives. The instrument was based on the Physical Activity and Leisure Motivation Scale (PALMS). The PALMS is a short form measurement that was developed from the validated version of the (PALMS) (27). The (PALMS) also measures the motivation of physically active individuals on a 5-point Likert scale(28). The Psychometric Properties the Farsi version of the (PALMS) (29) in the Iranian population was assessed, and includes 40 items in subscales: competition, appearance, health, others' expectations, affiliation, psychological condition, enjoyment, mastery, financial gain, and to be with others. All items were rated from $0=$ "Not at all true for me" to $5=$ "very true for me." The (PALMS) reliability was supported with a high internal consistency of 0.91 and a high test-retest reliability of 0.97 (95\% Cl: 0.97-0.98). The association between the (PALMS) and its previous version, the (PALMS), was strongly significant $(r=0.86, P$ $<0.001$ ). The Factor Loadings of the Farsi version of the (PALMS) were from 0.40 through 0.83 and identified appearance ( 4 items; e.g., define muscle, look better, and improve appearance) and positive health ( 3 items; e.g., maintain a healthy body and keeps me healthy) subscales. In the present study, the (a) Cronbach reliability coefficient was .860 and .911 for the appearance and positive health subscales respectively.

Explicit exercise evaluations were measured using an adapted version of the Corbin attitude toward physical activity questionnaire. This scale includes 9 domains in health, appearance, enjoyment, relaxation, 
challenge, social, competition, and outdoors reflecting intrinsic and extrinsic motivation. A mean score was created with responses to 18 items, on a scale ranging from 0 (not at all true for me) to 5 (very true for me). Some examples of items: for my health, I need to do regular exercise, when I do regular physical activity, I feel more physically attractive and when I exercise or exercise, enjoy it. The internal consistency for this scale was 0.76 for boys and for girls 0.77 and 0.75 in totally. The Cronbach's alpha coefficient was 0.92 . The Corbin attitude toward physical activity scale applied to measure motives for participating in PA among Iranian high school and university students to assess attitude toward PA(30,31). The (a) Cronbach reliability coefficient of this study was 0.91 .

The Farsi self-regulation scale measured of self-regulation mechanisms in the past 4 weeks by propositions of 4-point Likert scale 0 (not true for me) to 4 (very true for me)(32). There are 24-items with six sub-scales measuring intrinsic regulation (e.g., I feel a lot of personal satisfaction when involved in the activity; 4 items, $a=.73$ ), integrated regulation (e.g., I exercise because participation in my sport is an integral part of my life ; 4 items, $a=.78$ ), identified regulation (e.g., I exercise because training hard will improve my performance; 4 items, $a=.90$ ), external regulation (e.g., I exercise because it allows me to be well regarded by people that I know; 4 items, $a=.79$ ), introjected regulation(e.g., I exercise because I would feel bad if I was not taking time to do it; 4 items, $a=.80$ ) and amotivation (e.g., I don't seem to be enjoying my sport as much as I previously did; 4 items, $a=.75)$. A mean score was created for each subscale. The Farsi self-regulation instrument had satisfactory Cronbach's alpha coefficients $0.80(0.69-0.78)$ and an acceptable model fit showed the values Adjusted Goodness of Fit Index (AGFI) 0.92, GFI (Goodness of fit); 0.95, Normed Fit Index (NFI) 0.95 and Root Mean Square Error of Approximation (RMSEA) of 0.083 represent an excellent model fit.

Social Desirability This scale is one of the most frequently used measures of social desirability, particularly among children and a previous paper has justified its use for children for examining the links between social desirability and self-reported physical activity $(33,34)$. The 33-item Farsi Version of the Social Desirability (FVSD) (35) is adapted from the Marlowe-Crowne Social Desirability Scale(36). Each item was rated as true (1) or false ( 0 ). A sum score of the items rated 'true' is a measure of whether a person behaves in a socially desirable way. The negative items were reverse-scored, and the total score ranged from 0 to 33 . The scores between 0 to 8,9 to 19, and 20 to 33 indicate low, moderate, and high levels of social desirability, respectively(37). Those who score high on this scale have a tendency to present themselves in a socially acceptable manner which conforms to others' expectations. Some items included in this scale are 'I have never intensely disliked anyone, 'I sometimes feel resentful when I don't get my way. The (FVSD) has been shown to be psychometrically sound, to measure social desirability in an Iranian sample. The goodness-offit of (FVSD) was demonstrated Chi-square (1200.954), X²/df (2.426), (RMSEA) (0.043), (AGFI), (NFI) (0.888), and (GFI) (0.901). All goodness-of-fit indexes were in the acceptable range. The reliability of the (FVSD) was supported with a high internal consistency of 0.702 . In the present study, The Cronbach's alpha of the (FVSD) was examined with 67 participants (34 males and 33 females aged 15-17 years and showed reliability of 0.95 .

\section{Data analysis}


D' scores were calculated from the GNATs as advised (Nosk \& Banaji, 2001). Responses were screened for errors, and response times slower than $250 \mathrm{msec}$ ( $0.5 \%$ of all trials). Response time was determined as the time from the stimulus onset to the key-press response. Omission errors were also excluded ( $1 \%$ of all trials). Implicit outcome measures were calculated by subtracting the mean score of the response to desirable and exercise from undesirable and exercise trials. A score close to zero meant no association, a positive score indicates evaluating exercise as pleasant and a negative score as evaluating exercise as unpleasant.

The moderation analyses followed a similar plan to Hyde et al. (2010) but, similarly to Berry et al. (2016) used multivariate linear regression models in which multiple outcomes are regressed simultaneously on the predictors, with interaction terms between implicit associations and the moderators. All models included gender, age, (MVPA), and implicit associations and one of the possible moderators, and interaction terms between the implicit associations and each moderator variable. All variables were mean centred before inclusion in the models.

\section{Results}

Complete data were obtained from 500 Iranian adolescents, aged $16-18$ years ( $M=16.73$ [SD = .731] of whom 269 (54.9\%) were female. However, 29 participants made excessive errors on the (GNATs) leaving a final sample for analysis $=471$.

Regression models. Table 1 shows the means, standard deviations, and correlations between all variables included in the models. Separate models assessed attitudes, each of the behavioral regulations and social desirability because a multivariate regression with all predictors in one model showed issues with multicollinearity (several tolerance values $<.05$ and variance inflation factors $>11$ ). Table 2 summarizes the regression models. For parsimony of space, age, gender, and (MVPA) are not reported, and only the beta weights for the final models are shown. In the health models, but not the appearance models, (MVPA) was a significant predictor of health motivation. Neither sex nor age were significant in any of the models. 
Table 1

Correlations and Means for all outcome and moderator variables

\begin{tabular}{|c|c|c|c|c|c|c|c|c|c|c|c|}
\hline Variable & $M(S D)$ & 1 & 2 & 3 & 4 & 5 & 6 & 7 & 8 & 9 & 10 \\
\hline $\begin{array}{l}\text { 1. Health } \\
\text { motive }\end{array}$ & $\begin{array}{l}2.74 \\
(1.59)\end{array}$ & - & & & & & & & & & \\
\hline $\begin{array}{l}2 . \\
\text { Appearance } \\
\text { motive }\end{array}$ & $\begin{array}{l}2.87 \\
(1.56)\end{array}$ & .02 & - & & & & & & & & \\
\hline $\begin{array}{l}\text { 3. Implicit } \\
\text { health }\end{array}$ & $\begin{array}{l}.23 \\
(.42)\end{array}$ & .12 & .05 & - & & & & & & & \\
\hline $\begin{array}{l}\text { 4. Implicit } \\
\text { appearance }\end{array}$ & $\begin{array}{l}.26 \\
(.45)\end{array}$ & $<.01$ & -.02 & .08 & - & & & & & & \\
\hline 5. Attitudes & $\begin{array}{l}3.03 \\
(.59)\end{array}$ & .001 & .01 & -.01 & .04 & - & & & & & \\
\hline $\begin{array}{l}\text { 6. External } \\
\text { regulation }\end{array}$ & $\begin{array}{l}1.21 \\
(.74)\end{array}$ & -.19 & .002 & .002 & .03 & -.14 & - & & & & \\
\hline $\begin{array}{l}7 . \\
\text { Introjected } \\
\text { regulation }\end{array}$ & $\begin{array}{l}.78 \\
(.66)\end{array}$ & -.12 & -.05 & .006 & -.02 & -.07 & .47 & - & & & \\
\hline $\begin{array}{l}\text { 8. Identified } \\
\text { regulation }\end{array}$ & $\begin{array}{l}.80 \\
(.77)\end{array}$ & -.02 & .03 & -.08 & -.06 & .01 & .02 & .04 & - & & \\
\hline $\begin{array}{l}9 . \\
\text { Integrated } \\
\text { regulation }\end{array}$ & $\begin{array}{l}1.03 \\
(.77)\end{array}$ & .02 & .006 & -.05 & -.04 & .02 & -.11 & .02 & .79 & - & \\
\hline $\begin{array}{l}\text { 10. Intrinsic } \\
\text { regulation }\end{array}$ & $\begin{array}{l}.79 \\
.(.78)\end{array}$ & -.03 & .03 & -.06 & -.05 & .02 & .01 & .04 & .96 & .79 & - \\
\hline $\begin{array}{l}\text { 11. Social } \\
\text { desirability }\end{array}$ & $\begin{array}{l}20.83 \\
(10.22)\end{array}$ & .02 & .02 & -.005 & -.03 & -.08 & .005 & -.02 & -.02 & .04 & -.02 \\
\hline${ }^{\star} p<.05 ; * \star p$ & $01 ; * \star \star *$ & .001 & & & & & & & & & \\
\hline
\end{tabular}


Table 2

Summaries of regression models with standardized coefficients; ${ }^{*} p<.05 ; * \star p<.01 ; * \star * p<.001$

\begin{tabular}{|c|c|c|c|c|c|c|}
\hline Moderator & Model & $\begin{array}{l}\beta \\
\text { implicit } \\
\text { health }\end{array}$ & $\begin{array}{l}\beta \text { implicit } \\
\text { appearance }\end{array}$ & $\stackrel{\beta}{\text { Moderator }}$ & $\begin{array}{l}\beta \text { Health } \\
\text { moderator } \\
\text { interaction }\end{array}$ & $\begin{array}{l}\beta \text { Appearance } \\
\text { moderator } \\
\text { interaction }\end{array}$ \\
\hline \multirow[t]{4}{*}{ Attitudes } & $\begin{array}{l}\text { Health } \mathrm{R}^{2} \\
=.08^{\star \star \star}\end{array}$ & $.12^{\star \star}$ & .002 & -.02 & $.09 *$ & -.06 \\
\hline & $\begin{array}{l}\text { adjusted } \\
\mathrm{R}^{2}=.07\end{array}$ & & & & & \\
\hline & $\begin{array}{l}\text { Appearance } \\
\mathrm{R}^{2}=.01\end{array}$ & .05 & -.02 & .01 & .06 & -.02 \\
\hline & $\begin{array}{l}\text { adjusted } \\
\mathrm{R}^{2}=.001\end{array}$ & & & & & \\
\hline \multirow[t]{4}{*}{ Amotivation } & $\begin{array}{l}\text { Health } R^{2} \\
=.08^{\star \star \star \star}\end{array}$ & $.12^{\star \star}$ & -.01 & -.04 & -.06 & .02 \\
\hline & $\begin{array}{l}\text { adjusted } \\
\mathrm{R}^{2}=.06\end{array}$ & & & & & \\
\hline & $\begin{array}{l}\text { Appearance } \\
\mathrm{R}^{2}=.01\end{array}$ & .05 & -.03 & -.04 & $<.001$ & .04 \\
\hline & $\begin{array}{l}\text { adjusted } R^{2} \\
=-.004\end{array}$ & & & & & \\
\hline \multirow[t]{4}{*}{$\begin{array}{l}\text { External } \\
\text { regulations }\end{array}$} & $\begin{array}{l}\text { Health } \mathrm{R}^{2} \\
=.08^{\star \star \star}\end{array}$ & $.12^{\star \star}$ & -.007 & $-.11^{\star}$ & .21 & .01 \\
\hline & $\begin{array}{l}\text { adjusted } \\
\mathrm{R}^{2}=.06\end{array}$ & & & & & \\
\hline & $\begin{array}{l}\text { Appearance } \\
\mathrm{R}^{2}=.01\end{array}$ & .05 & -.03 & -.01 & .01 & -.01 \\
\hline & $\begin{array}{l}\text { adjusted } \\
\mathrm{R}^{2}=.007\end{array}$ & & & & & \\
\hline \multirow[t]{4}{*}{$\begin{array}{l}\text { Introjected } \\
\text { regulations }\end{array}$} & $\begin{array}{l}\text { Health } \mathrm{R}^{2} \\
=.09^{\star \star \star}\end{array}$ & $.12^{\star \star}$ & -.02 & $-.11^{\star}$ & $-.12^{\star}$ & .03 \\
\hline & $\begin{array}{l}\text { adjusted } \\
\mathrm{R}^{2}=.08\end{array}$ & & & & & \\
\hline & $\begin{array}{l}\text { Appearance } \\
\mathrm{R}^{2}=.01\end{array}$ & .05 & -.03 & -.04 & -.02 & -.005 \\
\hline & $\begin{array}{l}\text { adjusted } \\
\mathrm{R}^{2}=.005\end{array}$ & & & & & \\
\hline
\end{tabular}




\begin{tabular}{|c|c|c|c|c|c|c|}
\hline Moderator & Model & $\begin{array}{l}\boldsymbol{\beta} \\
\text { implicit } \\
\text { health }\end{array}$ & $\begin{array}{l}\beta \text { implicit } \\
\text { appearance }\end{array}$ & $\begin{array}{l}\boldsymbol{\beta} \\
\text { Moderator }\end{array}$ & $\begin{array}{l}\beta \text { Health } \\
\text { moderator } \\
\text { interaction }\end{array}$ & $\begin{array}{l}\beta \text { Appearance } \\
\text { moderator } \\
\text { interaction }\end{array}$ \\
\hline \multirow[t]{4}{*}{$\begin{array}{l}\text { Integrated } \\
\text { regulations }\end{array}$} & $\begin{array}{l}\text { Health } R^{2} \\
=.08^{\star \star \star}\end{array}$ & $.12^{\star \star}$ & -.01 & -.02 & .06 & $.10^{*}$ \\
\hline & $\begin{array}{l}\text { adjusted } \\
\mathrm{R}^{2}=.07\end{array}$ & & & & & \\
\hline & $\begin{array}{l}\text { Appearance } \\
\mathrm{R}^{2}=.01\end{array}$ & .04 & -.02 & .02 & .05 & -.008 \\
\hline & $\begin{array}{l}\text { adjusted } \\
\mathrm{R}^{2}=.005\end{array}$ & & & & & \\
\hline \multirow[t]{4}{*}{$\begin{array}{l}\text { Identified } \\
\text { regulations }\end{array}$} & $\begin{array}{l}\text { Health } R^{2} \\
=.08^{\star \star \star}\end{array}$ & $.13^{\star \star}$ & -.01 & -.002 & .02 & $.10 * \star$ \\
\hline & $\begin{array}{l}\text { adjusted } \\
\mathrm{R}^{2}=.06\end{array}$ & & & & & \\
\hline & $\begin{array}{l}\text { Appearance } \\
\mathrm{R}^{2}=.01\end{array}$ & .05 & -.02 & .03 & .06 & -.002 \\
\hline & $\begin{array}{l}\text { adjusted } \\
\mathrm{R}^{2}=.003\end{array}$ & & & & & \\
\hline \multirow[t]{4}{*}{$\begin{array}{l}\text { Intrinsic } \\
\text { motivation }\end{array}$} & $\begin{array}{l}\text { Health } R^{2} \\
=.08^{\star \star \star}\end{array}$ & $.12^{\star \star}$ & -.01 & -.01 & .03 & $.10^{\star}$ \\
\hline & $\begin{array}{l}\text { adjusted } \\
\mathrm{R}^{2}=.07\end{array}$ & & & & & \\
\hline & $\begin{array}{l}\text { Appearance } \\
\mathrm{R}^{2}=.01\end{array}$ & .05 & -.02 & .03 & .04 & -.005 \\
\hline & $\begin{array}{l}\text { adjusted } \\
\mathrm{R}^{2}<.001\end{array}$ & & & & & \\
\hline \multirow[t]{4}{*}{$\begin{array}{l}\text { Social } \\
\text { desirability }\end{array}$} & $\begin{array}{l}\text { Health } \mathrm{R}^{2} \\
=.08^{\star \star \star}\end{array}$ & $.12^{\star}$ & -.006 & .01 & .02 & -.08 \\
\hline & $\begin{array}{l}\text { adjusted } \\
\mathrm{R}^{2}=.06\end{array}$ & & & & & \\
\hline & $\begin{array}{l}\text { Appearance } \\
\mathrm{R}^{2}=.03^{\star}\end{array}$ & .05 & -.03 & $<.001$ & .006 & $.15^{\star \star}$ \\
\hline & $\begin{array}{l}\text { adjusted } \\
\mathrm{R}^{2}=.01\end{array}$ & & & & & \\
\hline
\end{tabular}

Implicit health, and the health-attitude, health-introjected, appearance-integrated, appearance-identified and appearance-intrinsic interactions were significant predictors in the respective health models. There were no 
significant predictors in any of the appearance models. Follow up with simple slopes analysis with health motivation as the outcome variable showed participants with medium $(p=.008)$ to high $(p=.002)$ attitudes and negative implicit health scores had the lowest health motivation compared to participants with high to moderate attitudes and strongly positive implicit health scores. The slope for low attitudes was not significant $(p=.45)$. This graph is shown in Fig. 1. Participants with low $(p=.001)$ to moderate $(p=.02)$ introjected regulations and negative implicit health scores had the lowest health motivation compared to participants with low to moderate introjected regulations and strongly positive implicit health scores. The slope for high introjected regulations was not significant $(p=.89)$. This graph is shown in Fig. 2. Participants with low $(p=.02)$ social desirability and negative implicit appearance scores had the highest appearance motivation. The slope for moderate $(p=.65)$ and high $(p=.08)$ social desirability were not significant. This graph is shown in Fig. 3. None of the slopes for integrated and implicit health interaction, identified and implicit appearance interaction, or intrinsic and implicit appearance interaction were significant (all $p>.07)$.

\section{Discussion}

The hypothesis that exercise-related attitudes would moderate (IEDs) between implicit evaluations and external motivations was supported for health motivations. Among participants with moderate to high PArelated attitudes, stronger implicit evaluations were associated with higher motivations to be active for health. This relationship was not found in the appearance model. It suggests the adolescents in this sample focus on the potential of achieving positive health outcomes of exercise rather than physical appearance outcomes. These results differ from others, who found the opposite relationships in a sample of older Canadian adolescents; that is there were automatic associaitons of exercise with social and appearance outcomes, but not health outcomes. (59).

Some explanations may justify this finding. Firstly, outcome expectations are what a person predicts will result from performing a particular action (38). In this regard, exercise-related expected outcomes usually result from experience of doing ertain types of physical activities and the goal of performing them. Outcomes related to appearance are usually expected from performing a particular type of activity in gyms aimed at improving appearance and physical fitness. Using these gyms generally requires payment. Due to the economic deprivation of the study population, using such gyms was impossible or limited for most students(35). Further, physical and exercise activities generally take typically place at school especially for Iranian girls. The focus of these school-based activities is usually physical and mental health rather than physical appearance. Secondly, it is documented the cultural, social, economic, sexual, and racial differences influence exercise-related outcome expectations(38, 39). Therefore, it will be necessary to identify the preferred types of expectations using accurate measurement to conduct further research and intervene in adolescent's exercise participation and to maintain the behavior in this populations.

The current study measured automatic exercise evalations which may be different from what one explicitly reports about a particular behavior. Research has shown that explicitly assessed outcome expectations, particularly those connected to social image or physical appearance, have a relatively positive relationship with adolescents' exercise behaviour $(40,41)$. The role of parents in encouraging adolescents to achieve the expected health-related outcomes should also be considered. Increasing screen time(42) and prevalence of 
physical inactivity in Iranian children and adolescents(35) may contribute to prompting parents and their children to achieve outcomes related to health rather than appearance. Given that the implicit association measurement tool included the dimensions of physical (e.g. being healthy, being strong) and mental health (e.g. relaxed, good mood) more research should be done in the future to determine which of these dimensions was more desirable for Iranian adolescents.

Our results showed those who had the highest introjected regulations had the lowest health motivation compared to participants with low to moderate introjected regulations. It seems the lower the introjected regulations, the greater the concordance between implicit evaluations of exercise with health and explicit motives for health. This finding is also inconsistent to other research that found introjected regulations moderated of IEDs(7). It is possible that, in this particular sample, health was commonly and strongly linked with exercise by the pervasive societal pressures to have a healthy body. Teixeira et al(43), in a systematic review of exercise, physical activity, and self-determination theory, found mixed results for the role of introjected regulations and exercise. There was a trend for an increase in introjected regulations across stages of change and over time $(44,45)$. In the current study, we did not assess whether participants were beginner or expert exercisers (i.e., whether they were at early or later stages of change). It may be that there is an increase in introjected regulations among initiate exercisers. Gender differences might also be relevant to the mixed findings regarding introjected regulations relations with exercise, with a stronger relationship in females compared to males [e.g., $(46,47)$. It may be that participants in the current study felt internally pressured to exercise and some degree of guilt or shame if they did not exercise and achieved positive health consequences.

Introjected regulations might also contribute to unsustainable exercise to achieve health-related benefits. Participants with the strongest automatic evaluations of health and exercise and low introjected regulations had the strongest motivation. Researchers have found that executive functioning moderated relationships between automatic approach and avoid tendencies to exercise and activity behaviour or intentions to be active (Chevance, Yannick, Heraud, \& Boiche, 2018; Cheval, Sarrazin, Isoard-Gautheur, Radel, \& Friese, 2016) $(48,49)$. Others have also found that participants with lower automatic evaluations, combined with less ability to control their actions exercised for less time, but this relationship did not exist for participants with greater ability to exert cognitive control (Padin, Emery, Vasey \& Kiecolt-Glaser, 2017)(26). The results of the current study may indicate that participants who were less motivated by guilt or obligation and positive automatic evaluations were more motivated to be active for health outcomes. Future research should determine if participants with lower introjected regulations and strong positive evaluations of PA and health also have strong executive control.

In contrast to previous research(7), low social desirability moderated the appearance (IED). Participants with low social desirability and negative implicit appearance scores had the highest appearance motivation. Social desirability is a tendency to distort self-report in a favorable direction (50). In the current sample, social desirability may have influenced survey responses. For example self-presentation the largest proportion of variance in self-reported physical activity is attributable to differences in the social desirability. Further, the results may have been affected because the response to implicit tasks can be faked or changed, 
although at a lower level than explicit actions (51). In order to determine what the implicit measures really measure among Iranian adolescents, further validity and reliability testing is required with this population.

The following limitations of the study could be taken into account. Firstly, the social desirability issues already highlighted may have affected the findings. Further, this research is cross-sectional and longitudinal research is needed to understand the effects of (IEDs) on exercise behaviour among Iranian adolescents.

\section{Conclusions}

While implicit thoughts regarding PA have extensively researched in western countries, this study constitutes a useful contribution to the research literature because it explored, for the first time, (IEDs) in Iranian students. In particular, Iranian girls must follow norms such as not exercising outdoors or certain types of activities that are different from girls in Western societies. Thus, the results of this study can inform intervention targets with this population.

\section{Abbreviations}

IEDs: Implicit and explicit discrepancies; PA: Physical activity; SDT: Self-determination theory;

GNATs: Go/No go association tasks; PALMS: Physical activity and leisure motivation scale; AGFI: Adjusted goodness of fit index; RMSEA:Root mean square error of approximation;

FVSD: Farsi version of the social desirability

\section{Declarations}

\section{Ethics approval and consent to participate}

Prior to participation, investigators sent a written information sheet and consent form for the parents and participants to sign. The ethical committee of Kurdistan University of Medical Sciences approved the study by the Research Ethics Committee (ethics code: IR.MUK.REC.1398.202).

\section{Consent for publication}

Not applicable

\section{Availability of data and materials}

The datasets used and/or analyzed during the current study are available

from the corresponding author on reasonable request.

\section{Competing interests}

The authors declare that they have no competing interests. 


\section{Funding}

Not applicable

\section{Authors' contributions}

T.B.R performed the analyses, provided critical feedback and contributed to the interpretation of the findings and writing of the final manuscript. P. T contributed to the study design and interpretation of results and wrote the first draft and the final manuscript. K.S conceived the work, study design and contributed to data collection. T. P interpreted the results, drafted the manuscript. A.B contributed to interpretation of results. All authors contributed to revision of the manuscript and all read and approved the final manuscript.

\section{Acknowledgements}

We thank the Deputy of Research and Technology of Kurdistan University of Medical Sciences for providing financial supports.

\section{References}

1. Beauchamp MR, Crawford KL, Jackson B. Social cognitive theory and physical activity: Mechanisms of behavior change, critique, and legacy. Psychol Sport Exerc. 2019;42:110-7.

2. Joseph RP, Ainsworth BE, Mathis L, Hooker SP, Keller C. Utility of social cognitive theory in intervention design for promoting physical activity among African-American women: a qualitative study. Am J Health Behav. 2017;41(5):518-33.

3. Courneya KS, Conner M, Rhodes RE. Effects of different measurement scales on the variability and predictive validity of the "two-component" model of the theory of planned behavior in the exercise domain. Psychol Health. 2006;21(5):557-70.

4. Nigg CR, Lippke S, Maddock JE. Factorial invariance of the theory of planned behavior applied to physical activity across gender, age, and ethnic groups. J Sport Exercise Psy. 2009;10(2):219-25.

5. Brooks JM, Iwanaga K, Chiu CY, Cotton BP, Deiches J, Morrison B, et al. Relationships between selfdetermination theory and theory of planned behavior applied to physical activity and exercise behavior in chronic pain. Psychol Health Med. 2017;22(7):814-22.

6. Hyde AL, Doerksen SE, Ribeiro NF, Conroy DE. The independence of implicit and explicit attitudes toward physical activity: Introspective access and attitudinal concordance. J Sport Exercise Psy. 2010;11(5):387-93.

7. Berry TR, Rodgers WM, Markland D, Hall CR. Moderators of implicit-explicit exercise cognition concordance. J Sport Exerc Psychol. 2016;38(6):579-89.

8. Banting LK, Dimmock JA, Lay BS. The role of implicit and explicit components of exerciser self-schema in the prediction of exercise behaviour. J Sport Exerc Psychol. 2009;10(1):80-6.

9. Evans JS. Dual-processing accounts of reasoning, judgment, and social cognition. Annu Rev Psychol. 2008;59:255-78. 
10. Rebar AL, Schoeppe S, Alley SJ, Short CE, Dimmock JA, Jackson B, et al. Automatic evaluation stimulithe most frequently used words to describe physical activity and the pleasantness of physical activity. Front Psychol. 2016;7:1277.

11. Chevance G, Stephan Y, Héraud N, Boiché J. The association between implicit attitudes toward physical activity and physical activity behaviour: a systematic review and correlational meta-analysis. Health Psychol. 2018;37(3):257-61.

12. Greenwald AG, Poehlman TA, Uhlmann EL, Banaji MR. Understanding and using the Implicit Association Test: III. Meta-analysis of predictive validity. J Pers Soc Psychol. 2009;97(1):17.

13. Nosek BA. Moderators of the relationship between implicit and explicit evaluation. J Exp Psychol Gen. 2005;134(4):565.

14. Calitri R, Lowe R, Eves FF, Bennett P. Associations between visual attention, implicit and explicit attitude and behaviour for physical activity. Psychol Health. 2009;24(9):1105-23.

15. Manouchehri J, Tojari F, Soltanabadi S. Validity and reliability of measurement instrument for sport motivation scale in professional athletes in team sports of Iran. J Psychiatry. 2015;18(2):1-4.

16. Berry TR, Rodgers WM, Divine A, Hall C. The Relationship of Explicit-Implicit Evaluative Discrepancy to Exercise Dropout in Middle-Aged Adults. J Sport Exerc Psychol. 2018;40(2):92-100.

17. Lowe R, Norman P. Attitudinal approaches to health behavior: Integrating expectancy-value and automaticity accounts. Soc Personal Psychol Compass. 2013;7(8):572-84.

18. McFadden K, Berry TR, McHugh TF, Rodgers WM. What older adolescents expect from physical activity: Implicit cognitions regarding health and appearance outcomes. J Am Coll Health. 2018;66(3):202-8.

19. Plotnikoff RC, Costigan SA, Karunamuni N, Lubans DR. Social cognitive theories used to explain physical activity behavior in adolescents: a systematic review and meta-analysis. Prev Med. 2013;56(5):245-53.

20. Taymoori P, Rhodes RE, Berry TR. Application of a social cognitive model in explaining physical activity in Iranian female adolescents. Health Educ Res. 2010;25(2):257-67.

21. Yungblut HE, Schinke RJ, McGannon KR. Views of adolescent female youth on physical activity during early adolescence. J Sport Sci Med. 2012 11(1):39.

22. McFadden K, Berry TR, McHugh TF, Rodgers WM. What older adolescents expect from physical activity: Implicit cognitions regarding health and appearance outcomes. J Am Coll Health. 2018;66(3):202-8.

23. Muschalik C, Elfeddali I, Candel MJ, Crutzen R, de Vries H. Does the discrepancy between implicit and explicit attitudes moderate the relationships between explicit attitude and (intention to) being physically active? BMC Psychol. 2019;7(1):52.

24. Markland D, Tobin VJ. Need support and behavioural regulations for exercise among exercise referral scheme clients: The mediating role of psychological need satisfaction. Psychol Sport Exerc. 2010;11(2):91-9.

25. Deci EL, Ryan RM. Overview of self-determination theory: An organismic dialectical perspective. Handbook of self-determination research. In: Deci EL, Ryan RM, editors. Handbook of self-determination research. Rochester, NY: The University of Rochester Press; 2002. p. 3-3. 
26. Padin AC, Emery CF, Vasey M, Kiecolt-Glaser JK. Self-regulation and implicit attitudes toward physical activity influence exercise behavior. J Sport Exerc Psychol. 2017;39(4):237-48.

27. Rogers H, Morris T. An overview of the development and validation of the Recreational Exercise Motivation Measure (REMM). In: XI the European Congress of Sport Psychology - proceedings. Copenhagen 2003; 144.

28. Morris T, Rogers H. Measuring motives for physical activity. In: Sport and Chance of Life: International Sport Science Congress. Seoul, Korea: The Kansas Association for Health, Physical Education, Recreation, and Dance: Paper presented at the International Sport Science Congress, Seoul, Korea, 2004. p. 242-50.

29. Zarei S, Memari AH, Moshayedi P, Mosayebi F, Mansournia MA, Khoo S, et al. Psychometric Properties of Physical Activity and Leisure Motivation Scale in Farsi: an International Collaborative Project on Motivation for Physical Activity and Leisure. Arch Iran Med. 2016;19(2):704-11.

30. Ahmadi A, Malekshahi M. Description and Comparison of Students' Attitudes Toward Physical Activities in Terms of Sport Fields Chosen. Sport Psychology Studies. 2015;3(9):39 - 54.

31. Taheri HC, Esmaeili R, Poutafkand F, Salari H, Alipour-Raz M, Tavakoli M. The Relationship Between Anthropometric Measurements and Attitudes to Sports Activities Among Secondary School Students of North Khorasan Province in 2017. Journal of North Khorasan University of Medical Sciences. 2018;10(2):87-93.

32. Manouchehri J, Tojari F, Soltanabadi S. Validity and reliability of measurement instrument for sport motivation scale in professional athletes in team sports of Iran. Journal of Psychiatry. 2015;18(2):1-4.

33. Motl RW, McAuley E, DiStefano C. Is social desirability associated with self-reported physical activity? J Prev Med. 2005;40(6):735-9.

34. Jago R BT, Baranowski JC, Cullen KW, Thompson DI. Social desirability is associated with some physical activity, psychosocial variables and sedentary behavior but not self-reported physical activity among adolescent males. Health Educ Res. 2007;22(3):438-49.

35. Rostami-Moez M, Hazavehei SMM, Karami M, Karimi-Shahanjarini A, Nazem F, Rezapur-Shahkolai F. Decline in Physical Activity Among Iranian Girl Students Aged 10 to 16 and the Related Factors. Health Scope. 2017;6(4).

36. Crowne P, Marlowe D. A new scale of social desirability independent of psychopathology. J Consult Psychol. 1960;24(4):349.

37. Fard JH, Gorji MAH, Jannati Y, Golikhatir I, Bozorgi F, Mohammadpour R, et al. Substance dependence and mental health in northern Iran. Ann Afr Med. 2014;13(3):114-8.

38. Loehr VG, Baldwin AS, Rosenfield D, JA. S. Weekly variability in outcome expectations: Examining associations with related physical activity experiences during physical activity initiation. J Health Psychol. 2014;19(10):1309-19.

39. Wójcicki TR, Siobhan M, White SM, McAuley E, Sciences S. J Gerontol B Psychol Sci Soc Sci. 2009;64(1):33-40.

40. Plotnikoff RC, Costigan SA, Karunamuni N, Lubans DR. Social cognitive theories used to explain physical activity behavior in adolescents: a systematic review and meta-analysis. Prev Med. 
2013;56(5):245-53.

41. Taymoori P, Rhodes R, Berry TR. Application of a social cognitive model in explaining physical activity in Iranian female adolescents. Health Educ Res. 2010;25(2):257-67.

42. Mozafarian N, Motlagh ME, Heshmat R, Karimi S, Mansourian M, Mohebpour F, et al. Factors associated with screen time in Iranian children and adolescents: the CASPIAN-IV study. Int J Prev Med. 2017;8.

43. Teixeira PJ, Carraça EV, Markland D, Silva MN, RM. R. Exercise, physical activity, and self-determination theory: a systematic review. Int J Behav Nutr Phy. 2012;9(1):78.

44. Rodgers WM, Hall CR, Duncan LR, Pearson E, MI. M. Becoming a regular exerciser: Examining change in behavioural regulations among exercise initiates. Psychol Sport Exerc. 2010;11(5):378-86.

45. Daley AJ DJ. Self-determination, stage of readiness to change for exercise, and frequency of physical activity in young people. Eur J Sports Exerc Sci. 2006;6(4):231-43.

46. Duncan LR, Hall CR, Wilson PM, Jenny O. Exercise motivation: A cross-sectional analysis examining its relationships with frequence, intensity, and duration of exercise. Int J Behav Nutr Phys Act. 2010;7(1):7.

47. Wilson PM, Rodgers WM, Fraser SN, Murray TC. Relationships between exercise regulations and motivational consequences in university students. Res Q Exerc Sport. 2004;75(1):81-91.

48. Chevance G, Stephan Y, Héraud N, Boiché J. Interaction between self-regulation, intentions and implicit attitudes in the prediction of physical activity among persons with obesity. Health Psychol. 2018;37(3):257.

49. Cheval B, Sarrazin P, Isoard-Gautheur S, Radel R, Friese M. How impulsivity shapes the interplay of impulsive and reflective processes involved in objective physical activity. Pers Individ Dif. 2016;96:1327.

50. Paulhus DL. Measurement and control of response bias. In: Robinson JP, Shaver PR, editors. Measures of personality and social psychological attitudes. Journal of Personality and Social Psychology. San Diego, CA: Academic Press; Vol. 1; p. 17-59.

51. Conroy DE, Berry TR. Automatic affective evaluations of physical activity. Exerc Sport Sci Rev. 2017:54(4):230-7.

\section{Figures}




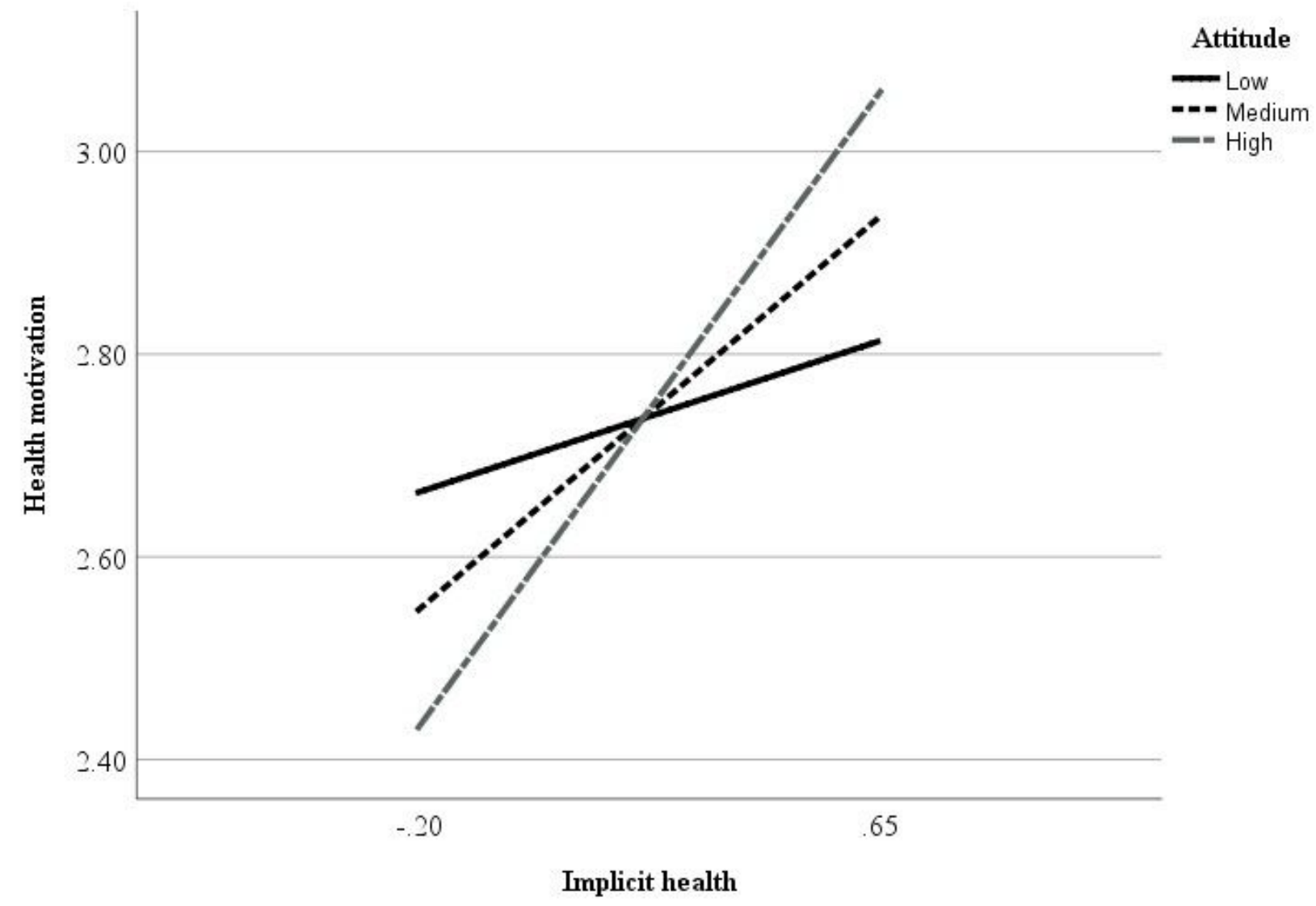

Figure 1

Simple slopes for the interaction between attitudes and implicit health predicting health motivation 


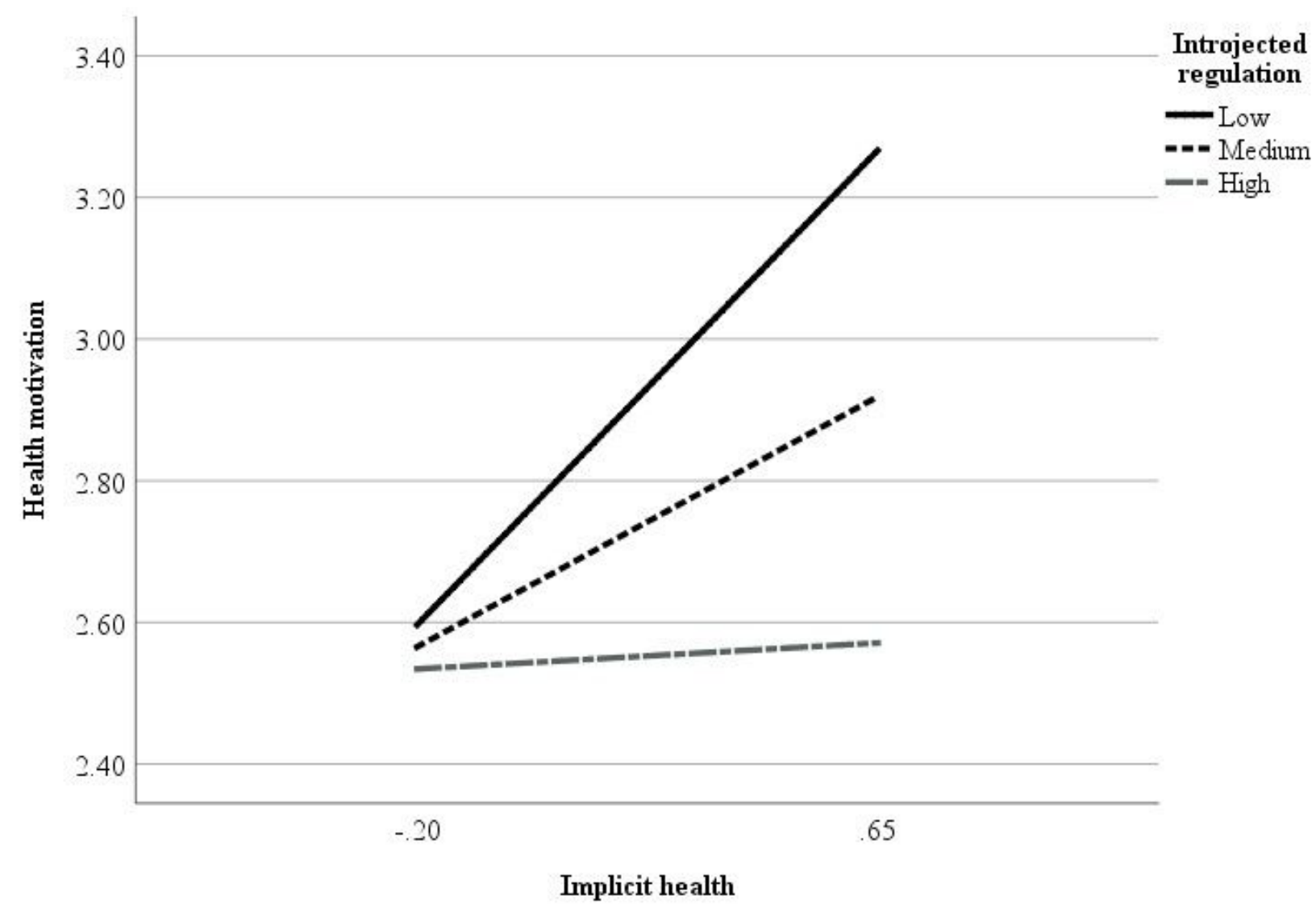

Figure 2

Simple slopes for the interaction between introjected regulation and implicit health predicting health motivation 


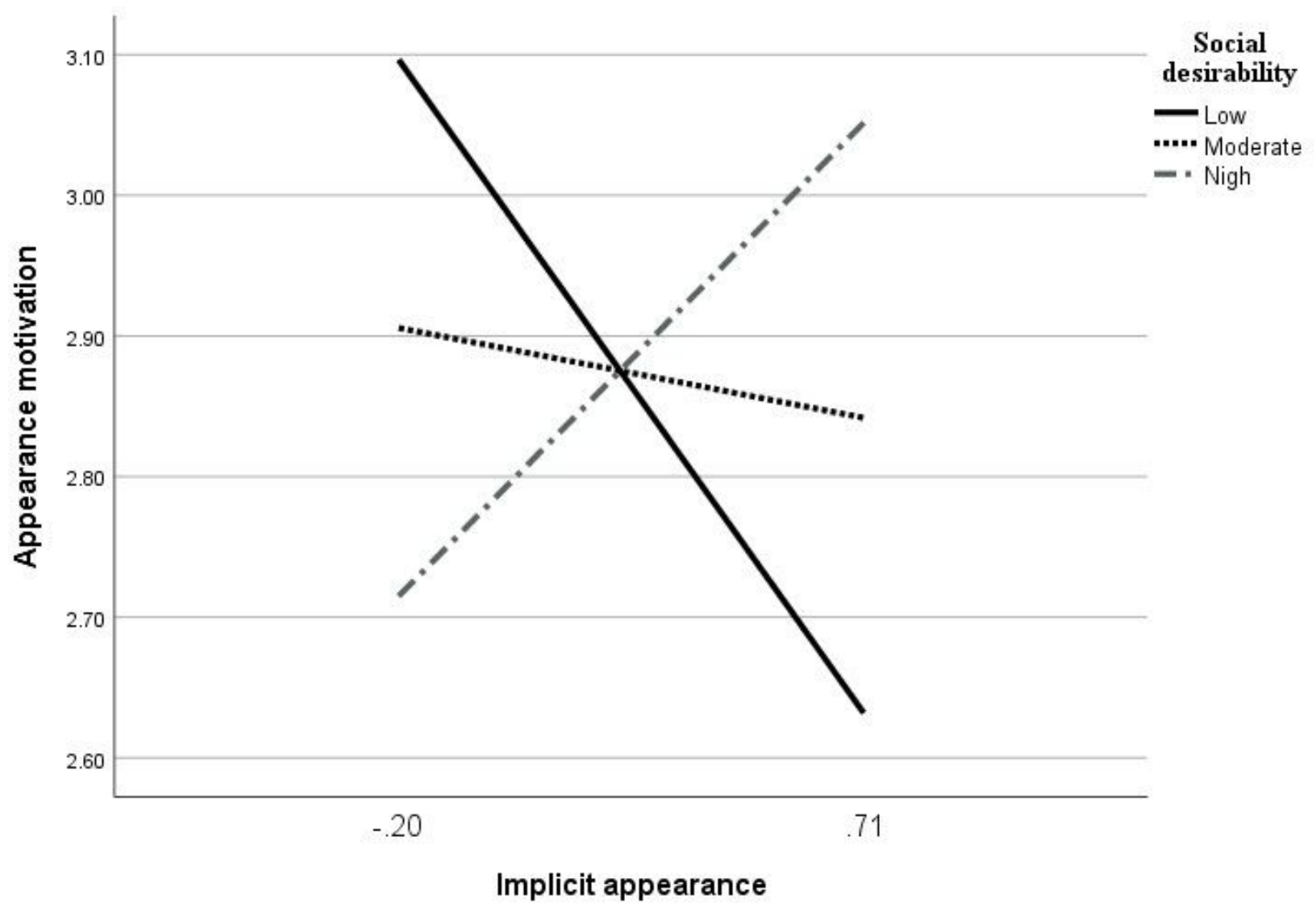

\section{Figure 3}

Simple slopes for the interaction between social desirability and implicit appearance predicting appearance motivation 